\title{
Integrated monitoring of slope processes in North Ossetia
}

\author{
$V B$ Zaalishvili $^{*}, D A$ Melkov $^{1}, N D$ Dobrev $^{2}, A S$ Kanukov $^{1}$ \\ ${ }^{1}$ Geophysical Institute of the Vladikavkaz Scientific Center of the Russian Academy of Sciences, \\ 362002, Vladikavkaz, Russia \\ ${ }^{2}$ Geological Institute "Str. Dimitrov", Bulgarian Academy of Sciences, Acad.G.Bonchevst. 1113, \\ Sofia, Bulgaria
}

\begin{abstract}
Landslides are one of the most destructive natural processes. The Loire landslide seems to be the reference object in this regard, it has absorbed all the extreme features of landslide structures known in the Central Caucasus, but has not revealed the secrets of its static state, the determination of which is the most important task of the scientific research. An active landslide formed as a result of anthropogenic activity (slope pruning) is also considered. The selected objects were examined by the geodetic and geophysical methods. Appropriate monitoring systems have been created.
\end{abstract}

\section{Introduction}

Slope processes are one of the most destructive natural processes that a person most often encounters during the mountainous areas' development. The greatest danger is unexpected and fast processes, like the collapse of the Kolka glacier in 2002 in the Karmadon gorge (Russia) or the collapse in the Devdorak glacier in 2014 (Georgia). Similar processes include landslide processes, which can be characterized by the slow displacements or unexpected rapid descent, the causes of which can be both the endogenous and exogenous processes [1-14].

Landslides are often formed on gentle slopes of the large mountain rivers and their tributaries' steep slopes, where high erosion potential is determined by the outcrops of bedrock of relatively low strength of sandy-clay composition such as siltstones, mudstones, marls, soft limestones, deployed dolomites and other semi-rock formations in combination with the extended in several $\mathrm{km} / \mathrm{km}^{2}$ erosion network and depths of local erosion bases of $1000-1500 \mathrm{~m}$.

Landslides are widely developed in the mountainous part of the Greater Caucasus and are the long-term forming geological objects. At the same time, the development dynamics, morphological and structural-lithological features, spatial characteristics and the static state of glaciers need to be investigated in detail and the opinion for the adoption of design decisions is given by the executive authorities.

* Corresponding author: vzaal@mail.ru 
The most dangerous for the designed and operating facilities in North Ossetia (Mizursky concentrator, a number of operating mines in gorges with mudflow hazardous slopes, Trankam, Zaramagskaya hydroelectric power station, the first stage of the Mamison tourist cluster) were studied in previous years during the above-mentioned design decisions and during the construction objects'industrial operation. As a result, it was found that the causes and mechanisms of landslide movement are quite diverse and are associated with both gravitational and climatic, as well as with seismotectonic processes occurring in the general cycle of neo-tectonic upward movements of the Greater Caucasus.

The Loire landslide seems to be the reference object in this regard, it has absorbed all the extreme features of landslide structures known in the Central Caucasus, but has not revealed the secrets of its static state, the determination of which is the most important task of the scientific research. The Loire landslide hangs menacingly over one of the obstinate water flows of the North Ossetia-Alania region - the Ardon River and is a potential threat to a number of settlements and the Transkam Federal Highway. It was this landslide that became the primary goal of monitoring the Geophysical Institute of the All-Russian Scientific Center RAS. In addition, two other objects of a smaller scale were selected for the study: the Zinsar landslide and a landslide in the area of the Fiagdon tailing dump, activated in 2019 as a result of cutting the slope.

\section{Geodetic monitoring}

Understanding the landslide behavior, first of all, requires characterization of both ground and underground kinematics $[15,16]$, and then the determination of possible trigger effects in the form of spatial and temporal strain measurements: measurements using inclinometers and extensometers, special GNSS geodetic methods, tachymetry and remote methods. Differential GPS measurements in combination with geophysical surveying are currently used all over the world to successfully record the landslide movements and identify the affected geological structures [17-21]. The technology of tomographic electrical resistance (ERT) has successfully proven itself in the study of deformation structures (Schrott\& Sass, 2008), and also makes it possible to create 2-, 3- and 4-D models [22] combined with surface topography.

Global Navigation Satellite Systems (GNSS) use decimeter phase measurements, and this has proven to be an effective tool for monitoring slope deformation. The samples include the work of Malet, Hartig, Calais and Maquaire [23, 24] in the French Alps using automatic GPS measurements and tachymetric and extenso-metric validations with an accuracy of several millimeters. Similar schemes were used to monitor the facilities in the territory of North Ossetia (Figures 1-3). Each benchmark was equipped with a reflector, allowing remote measurements using a total station. Modern technology provides total stations capable of measuring angles with an accuracy of 1 second and distances with an accuracy of $\pm 1 \mathrm{~mm}$. At distances up to $3500 \mathrm{~m}$ (accuracy decreases with distance). Total stations give an opportunity to measure the multiple points with prismatic targets on a controlled surface for a short period of time. Using Automatic Target Recognition (ATR) technology, it is possible to find each prism and determine its center to ensure accurate targeting. Such technologies are ideal for precise applications where the removal of error sources is desired. However, the use of a sufficient number of prisms for permanent installation on a slope is not economically feasible; the prisms are also the accurate optical devices that can easily be damaged not only as a result of vandalism, but also under the influence of natural factors. When carrying and installing the prism manually, the advantage of using a total station capable of taking measurements from a distance is lost. We have investigated various reflective surfaces to ensure stable measurement at large 
distances for the Loire landslide. The use of a robotic total station gives an opportunity to aim at the reflectors automatically, according to the previous measurements' results. The created system, although it requires the operator's participation to accurately point the reflector to the crosshair, nevertheless, the work on regular geodetic monitoring is significantly reduced. The disadvantage of using the total station surveys is the need for sight line to take the measurements. However, in all cases, for all objects, we were able to select survey points covering the most important areas for monitoring. In extreme cases, GPS technology can be used. Figure 1 shows the monitoring system of the Loire Landsli deas an example. Shooting is performed from the opposite slope. A point with a concrete foundation up to 0.5 meters deep was laid; the current geodetic point was used as the second reference point. The distance to the distant reflectors is more than $1 \mathrm{~km}$. The measurements are taken by a Trimble S7 total station. An example of scanning a slope of a small landslide (Fiagdon tailing dump) is shown in Figure 4.

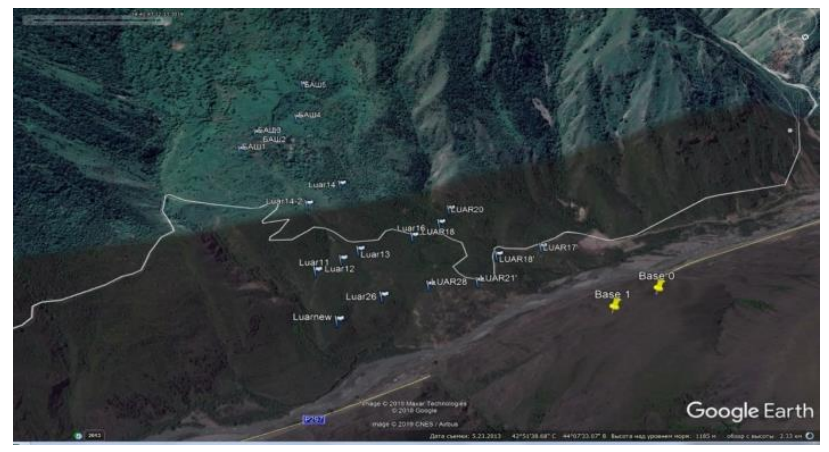

Fig. 1.The system of the Loire landslide geodetic monitoring

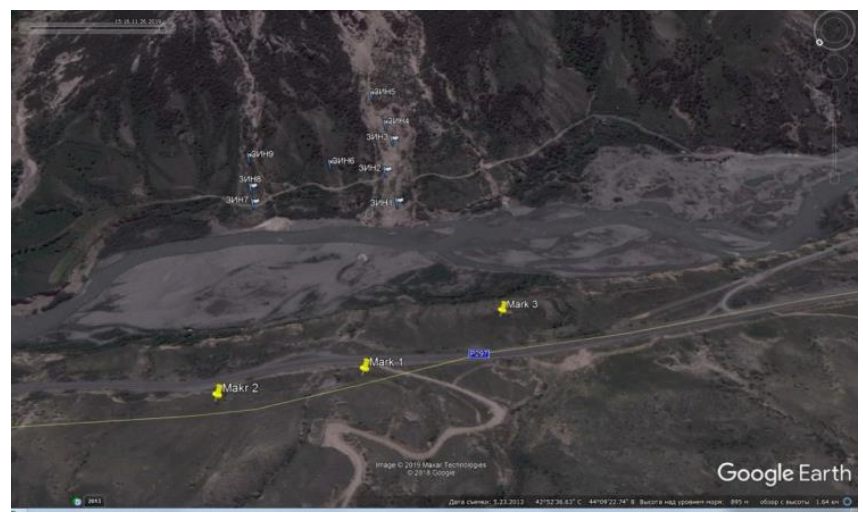

Fig. 2. Zincar landslide geodetic monitoring system

\section{Geophysical surveys}

The geological characteristics of the Loire landslide are derived from the stock materials) and the work was performed in 2019. The data of 8 boreholes were used to compile the geological and geophysical sections together with the data of vertical electric sounding 29 points, performed on the spans $\mathrm{AB} / 2=325 \mathrm{~m}$. To study the landslide's upper part structure, three profiles of geolocation sounding were performed by the OKO-2 Georadar at the frequencies of $150 \mathrm{MHz}$. 
In seismic observations of the seismic type, the vertical (for calculating the longitudinal wave propagation velocity) and horizontal (for calculating the transverse wave propagation velocity) the elastic wave components in the ground were recorded. A system of single and multiple observation and recording of oncoming travel time curves of longitudinal and transverse waves was used.

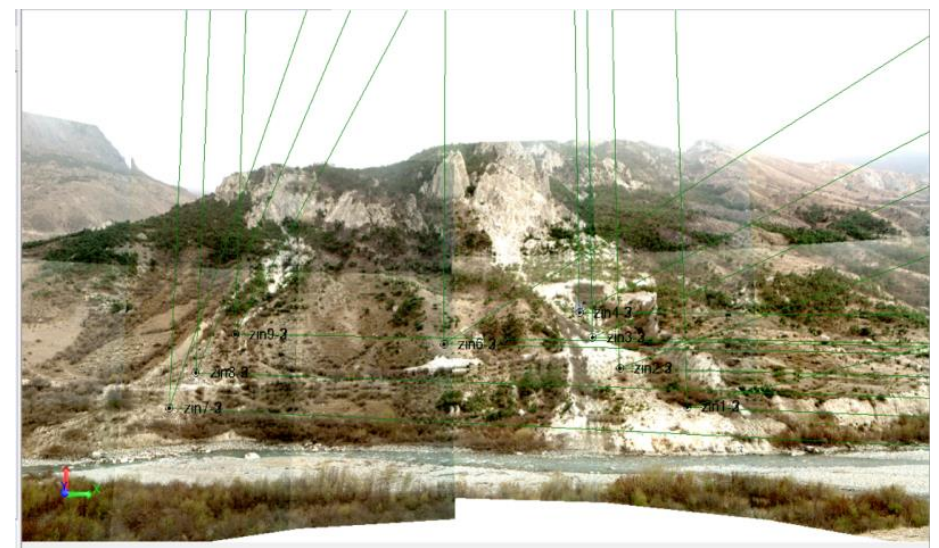

Fig. 3. View of the Zincar landslide from the shooting point

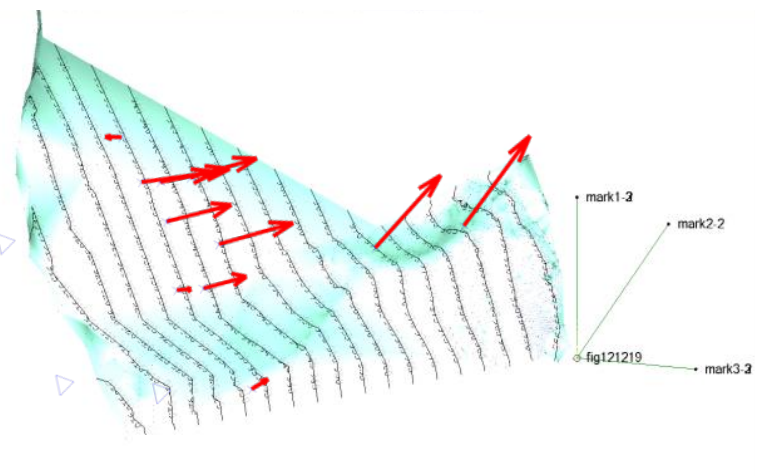

Fig. 4. Digital surface model calculated from a point cloud; the arrows indicate the reference points' offsets.

Parameters and main technical characteristics of the used Lakkolit X-M2 digital seismic equipment (the number of simultaneously recorded channels is 24 , the range of the recorded frequencies is $5-4000 \mathrm{~Hz}$; the $\mathrm{ADC}$ resolution is 24 ; the seismic receivers are SG20 and SV-20.) The main processing volume and interpretation of seismograms was carried out on the computer programs Radex Pro Plus version 3.75basis.

\section{Conclusion}

The increased interest in the geological hazards' study leads to the development of new remote technologies for measuring and monitoring and the creation of digital terrain models. The best way to determine slope deformation is to use an integrated approach combining interdisciplinary approaches in morphological analysis, monitoring and interpretation of slope kinematics and appropriate risk identification. The synergistic use of technology in combination provides a wide range of data and information for decision 
making. The ground method determines the actual state of a landslide, and the use of GNSS and total station measurements provides an affordable and effective technology for measuring small deformations. The choice of methods is determined by their advantages and disadvantages. The GPS technology disadvantages are the long observation time of 30 minutes per point, the need to stabilize the establishment of a network point and accuracy (especially vertical). The accuracy depends on the device accuracy, data transfer processing, weather conditions, coordinate conversion from WGS84 to the local coordinate system. Photogrammetric data provides high-resolution spatial datasets for topographic modeling, landslide identification and differentiation. Nevertheless, vegetation remains the main problem of the photogrammetric data. This limits the vegetation and landslides' reliability, where significant errors are associated with grass cover or small trees and shrubs. The use of robotic total stations makes it possible to increase the number of ground points - benchmarks, while monitoring remotely, including in reflection less mode. Geodetic methods allow monitoring only the surface. However, the processes initiating the masses movement can occur at depth, without noticeable surface changes. Therefore, geophysical methods can be used for the following monitoring types: georadar sounding, seismic exploration, electrical exploration.

The research was supported by Russian Science Foundation (Project No. 19-47-02010 RSF -DST (2018):"Natural hazards and monitoring for mountain territories in Russia and India".

\section{References}

1. V. Zaalishvili, N. Nevskaya, L. Nevskii, Shempelev Journal of Volcanology and Seismology 9(5), 333-338 (2015).

2. A. Gorbatikov, E. Rogozhin, M. Stepanova, Y. Kharazova, N. Andreeva et. al, Izvestiya. Physics of the Solid Earth 51(1), 26-37 (2015).

3. O. Burdzieva, V. Zaalishvili, O. Beriev, A. Kanukov, M. Maisuradze, International Journal of GEOMATE 10(1), 1693-1697 (2016).

4. A. Shempelev, V. Zaalishvili, S. Kukhmazov, Geotectonics 51(5), 479-488 (2017).

5. V. Zaalishvili, A. Kanukov, D. Melkov, V. Makiev, L. Dzobelova, International Journal of GEOMATE 15(51), 160-166 (2018).

6. V. Zaalishvili, N. Nevskaya, L. Nevskii, A. Shempelev, Journal of Volcanology and Seismology 9(5), 333-338 (2015).

7. V. Zaalishvili, D. Melkov, A. Kanukov, B. Dzeranov, V. Shepelev, International Journal of GEOMATE 10(1), 1670-1674 (2016).

8. V. Zaalishvili, D. Melkov, B. Dzeranov, F. Morozov, G. Tuaev, International Journal of GEOMATE 15(47), 158-163 (2018).

9. V. Zaalishvili, D. Melkov, A. Kanukov, B. Dzeranov, International Journal of GEOMATE 10(1), 1656-1661 (2016).

10. V. Zaalishvili, D. Melkov, Izvestiya. Physics of the Solid Earth 50(5), 707-718 (2014).

11. V. Zaalishvili, A. Dzhgamadze, D. Gogichev, B. Dzeranov, O. Burdzieva, International Journal of GEOMATE 15(51), 22-30 (2018).

12. V. Zaalishvili, Measurement Techniques 58(12), 1297-1303 (2016).

13. V. Zaalishvili, N. Nevskaya, D. Melkov, Izvestiya. Physics of the Solid Earth 50(2), 263-272 (2014). 
14. V. Milyukov, V. Yushkin, A. Kopaev, et.al., Measurement Techniques 56(10), 1105 1110 (2014).

15. J. Busa, M. Rusnak, D. Kusnirak, V. Greif, M. Bednarik, et.al., Physical Geography 41(2), 169-194 (2020). doi:10.1080/02723646.2019.1630232

16. C. Delacourt, P. Allemand, E. Bertier, D. Raucoules, B. Casson, et.al., Bulletin De La Société Géologique De France 178, 89-100 (2007).

17. G. Bievre, D. Jongmans, D. Goutaland, E. Patheir, V. Zumbo, Landslides 13, 423-436 (2016)

18. A. Godio, C. Strobbia, G. De Bacco, Engineering Geology 83, 273-286 (2006).

19. D. Jongmans, S. Garambois Bulletin De LaSociétéGéologique De France, 178, 101112 (2007).

20. V. Pazzi, L. Tanteri, G. Bicocchi, M. D’Ambrosio, A. Caselli, R. Fanti, Physics and Chemistry of the Earth 98, 136-153 (2017)

21. J. Soto, P. Galve, J. Palenzuela, M. Azaňón, J. Tamay, C. Irigaray, Landslide 14(6), 1929-1947 (2017).

22. M. Loke, J. Chambers, D. Rucker, O. Kuras, P. Wilkinson, Journal of Applied Geophysics 95, 135-156 (2013)

23. J. Malet, S. Hartig, E. Calais, O. Maquaire, Comptes Rendus Del' Académie Des Sciences - Series IIA - Earth and Planetary Science 331(3), 175-182 (2000).

24. J. Malet, O. Maquaire, E. Calais, Geomorphology 43, 33-54 (2002). 